\title{
Influences of hand posture and hand position on compatibility effects for up-down stimuli mapped to left-right responses: Evidence for a hand referent hypothesis
}

\author{
YANG SEOK CHO and ROBERT W. PROCTOR \\ Purdue University, West Lafayette, Indiana
}

\begin{abstract}
Unimanual left-right responses to up-down stimuli show a stimulus-response compatibility (SRC) effect for which the preferred mapping varies as a function of response eccentricity. Responses made in the right hemispace and, to a lesser extent, at a midline position, are faster with the up-right/ down-left mapping than with the up-left/down-right mapping, but responses made in the left hemispace are faster with the up-left/down-right mapping. Also, for responses at the midline position, the preferred mapping switches when the hand is placed in a supine posture instead of the more usual prone posture. The response eccentricity effect can be explained in terms of correspondence of asymmetrically coded stimulus and response features, but it is not obvious whether the hand posture effect can be explained in a similar manner. The present study tested the implications of a hypothesis that the body of the hand provides a frame of reference with respect to which the response switch is coded as left or right. As was predicted by this hand referent hypothesis, Experiment 1 showed that the influence of hand posture (prone and supine) on orthogonal SRC was additive with that of response location. In Experiment 2, the location of the switch relative to the hand was varied by having subjects use either a normal grip in which the switch was held between the thumb and the index finger or a grip in which it was held between the little and the ring fingers. The magnitudes of the mapping preferencesvaried as a function of the grip and hand posture in a manner consistent with the hand referent hypothesis.
\end{abstract}

For two-choice reaction tasks in which the stimuli and the responses vary along the same dimension (either horizontal or vertical), responses are faster and more accurate when each stimulus is mapped to its corresponding response than when the mapping is reversed (e.g., Shaffer, 1965; Vu, Proctor, \& Pick, 2000). This stimulus-response (S-R) compatibility (SRC) effect is attributed to spatial coding of the stimulus and the response sets, with response selection being faster when the stimulus and the response codes correspond than when they do not (e.g., Hommel, 1997; Kornblum, Hasbroucq, \& Osman, 1990; Umiltà \& Nicoletti, 1990). Although coding of the two stimulus locations as left and right with respect to each other and coding of the two responses in a similar manner predominates, spatial coding occurs with respect to multiple frames of reference (e.g., Hommel \& Lippa, 1995; Lamberts, Tavernier, \& d'Ydewalle, 1992; Roswarski \& Proctor, 1996).

Similar SRC effects occur in two-choice tasks when the stimulus and the response sets vary along orthogonal dimensions. Bauer and Miller (1982) had subjects respond to stimuli located above or below fixation with unimanual

We thank Jos Adam, Albrecht Inhoff, Claire Michaels, Yvonne Lippa, and Wolfgang Prinz for comments on previous versions of the manuscript. Correspondence concering this article should be sent to Y. S. Cho, Department of Psychological Sciences, Purdue University, West Lafayette, IN 47907-1364(e-mail: yscho@psych.purdue.edu). left-right movements of the index finger, using the left or the right hand. The results showed shorter reaction times (RTs) when the up stimulus was mapped to the right response and the down stimulus to the left response (the upright/down-left mapping) than when the S-R assignments were reversed, with this up-right/down-left advantage being smaller for the right hand than for the left hand. Bauer and Miller's findings led to numerous studies on orthogonal SRC effects (see Cho \& Proctor, in press, for a review). Lippa and Adam (2001) suggested that two types of orthogonal SRC effects can be distinguished: (1) an overall advantage of the up-right/down-left mapping and (2) mapping preferences that vary with the responding hand or the position of the response device (called the response eccentricity effect).

\section{The Up-Right/Down-Left Advantage}

Bauer and Miller (1982) concluded that their results could not be explained in terms of spatial coding in response selection, because there was no spatial correspondence between the stimulus and the response locations that was maintained for one mapping but not for the other, as in typical spatial SRC effects. However, Weeks and Proctor (1990) proposed that the overall up-right/down-left advantage in Bauer and Miller's study could be explained in terms of known properties of coding. Their explanation was based on the salient features coding principle, pro- 
posed originally by Proctor and Reeve (1985, 1986), according to which response selection is faster when the salient features of the stimulus and the response sets correspond than when they do not. This principle is supported by numerous findings from four-choice tasks in which responses are made by pressing keys with the index and middle fingers of the left and right hands and stimuli are two-dimensional symbols or a row of spatial locations precued in pairs (see Reeve \& Proctor, 1990, for a review). It also is supported by results for four-choice tasks in which the stimuli are auditory consonant-vowel combinations and/or the responses are similar vocal utterances (Proctor, Dutta, Kelly, \& Weeks, 1994) and for two-choice tasks in which the stimuli and the responses vary along both vertical and horizontal dimensions (Vu \& Proctor, 2002). The crux of the principle is that performance is best when the structure inherent in the stimulus set is mapped consistently to the structure inherent in the response set.

For two-choice tasks in which both the stimuli and the responses vary along only a single dimension, it is less obvious that structural correspondence could be a factor. However, Weeks and Proctor (1990) argued that there is, in fact, structure to the stimulus and response sets in these situations because the stimuli and the responses are coded asymmetrically. The central idea is that coding is relational, with one of the two alternatives within each set serving as the referent and the other being coded relative to it. Considerable evidence from sentence-picture verification tasks indicates that $u p$ serves as the polar referent for the vertical dimension and right as the polar referent for the horizontal dimension, with down and left coded relative to their respective referents (Chase \& Clark, 1971; Just \& Carpenter, 1975; Olson \& Laxar, 1973, 1974; see Cho \& Proctor, in press, for a review). In the literature on verification tasks, the terminology of lexical marking has been used extensively, with up and right called unmarked and down and left called marked. Because Weeks and Proctor did not restrict asymmetric coding to linguistic representations, they continued to use the terminology of salient features coding, calling the referent the salient feature of the dimension. The important point, however, is that even in two-choice tasks, the two members of the stimulus and the response sets are not coded equivalently.

On the basis of the independent evidence from verification tasks for classifying $u p$ and right as salient, Weeks and Proctor (1990) tested several predictions derived from the principle that performance should be best when the structure of the stimulus set is preserved in the mapping to the response set. Because there is correspondence of the more salient (and less salient) codes for the up-right/ down-left mapping but not for the up-left/down-right mapping, Weeks and Proctor's account predicted that the up-right/down-left advantage would be a pervasive phenomenon obtained with a variety of stimulus and response sets. Weeks and Proctor demonstrated that the up-right/ down-left advantage occurs not only with unimanual aimed movements at body midline, but also with bimanual keypresses and vocal "left"-"right" responses. They also showed that the advantage occurs when the location information is conveyed by arrow stimuli, and subsequent research has shown that it extends as well to the visual words "left" and "right" (Proctor, Wang, \& Vu, 2002).

Umiltà (1991) and Adam, Boon, Paas, and Umiltà (1998) proposed an alternative account for the up-right/ down-left advantage that they call the dual-strategy hypothesis. This account also attributes the up-right/downleft advantage to correspondence of asymmetric stimulus and response codes but assumes that this asymmetry is a property of verbal codes, and not of spatial codes. Consequently, the dual-strategy hypothesis predicts that the up-right/down-left advantage will be present only when verbal coding is used and that factors that increase the use of verbal coding will enhance the advantage. Cho and Proctor (2001) and Proctor and Cho (2001) obtained evidence that asymmetric coding is not restricted to verbal codes. Regardless, the salient features and dual-strategy accounts are in agreement in attributing the up-right/ down-left advantage to correspondence of asymmetric stimulus and response codes.

\section{The Response Eccentricity Effect}

Although the up-right/down-left advantage is often found with left-right unimanual movements (of a finger, switch, or joystick), the magnitude and direction of this orthogonal SRC effect is influenced by the location at which the responses are made along a frontoparallel line on the transverse plane. Michaels provided the first demonstration of this phenomenon, called the response eccentricity effect. In her Experiment 1, subjects made unimanual left-right toggle-switch responses to vertically arrayed stimuli at three response locations for each hand: midline and ipsilateral eccentricities of 30 and $60 \mathrm{~cm}$. At midline, both hands showed an up-right/down-left advantage. However, at the ipsilateral eccentricities, the up-right/ down-left advantage increased for the right hand but reversed to an up-left/down-right advantage for the left hand. Michaels (1989) interpreted this response eccentricity effect in terms of an ecological framework, according to which the "the state of the action system 'sets up' perception" (p. 263).

In Michaels's (1989) experiment, subjects grasped the switch with the palm down (a prone posture) at body midline but with the palm inward (a more supine posture) at the eccentric locations. Michaels and Schilder (1991) controlled hand posture in their Experiment 1 by ensuring that the same posture was adopted at the midline and the ipsilateral response positions. This was accomplished by having subjects hold a block of wood, with the index finger inserted between two microswitches. The finger was deflected to the left or the right in response to an up or a down stimulus. This experiment yielded a response eccentricity effect similar to that found by Michaels, consistent with her hypothesis that the state of the action system at different hand positions results in different orthogonal SRC effects. Michaels and Schilder accepted Bauer and Miller's (1982) position that the structure of the motor sys- 
tem influences SRC but proposed further "that not only the structure of the motor system, but also its current organizational state, can condition perception" (Michaels \& Schilder, 1991, p. 347).

If it is assumed that the orthogonal SRC effects that vary with response eccentricity are due to the structure and organization of the motor system, whereas the upright/down-left advantage is due to correspondence of asymmetric stimulus and response codes, one is led to conclude that the two types of orthogonal SRC effects are fundamentally different. This is the position taken by Adam et al. (1998), who attributed the up-right/down-left advantage to correspondence of asymmetric verbal codes, and by Lippa and Adam (2001), who attributed the response eccentricity effect to end-state comfort of the movements for the responding hand. According to Lippa and Adam's end-state comfort hypothesis, an image of the response set is mentally rotated clockwise or counterclockwise to align the response dimension with the stimulus dimension, with the rotation being in the direction that would result in the most comfortable end-state posture if the hand were actually rotated. The preferred mapping is thus determined by the relative ease with which the responding hand can be rotated in one direction or the other.

Postulating different explanations for the up-right/ down-left advantage and the orthogonal SRC effects that vary with response eccentricity seems less than ideal from the standpoint of parsimony, particularly given that there is not a clear dividing line between the two types of effects. That is, an overall up-right/down-left advantage is usually evident, although not always statistically significant, in studies showing the response eccentricity effect (e.g., in Michaels \& Schilder's, 1991, Experiment 1, responses were approximately $10 \mathrm{msec}$ faster and $1.5 \%$ more accurate overall for the up-right/down-left mapping than for the alternative mapping). Correspondence of asymmetric $\mathrm{S}-\mathrm{R}$ codes, as hypothesized by Weeks and Proctor (1990), provides the only currently viable explanation of the up-right/down-left advantage, to which the endstate comfort and ecological accounts are not applicable. Therefore, it is important to pursue the possibility that the response eccentricity effect is also due primarily to correspondence of asymmetric S-R codes.

Obviously, the response eccentricity effect cannot be explained if it is assumed that up and right are always more prominent then down and left, a point acknowledged indirectly by Weeks and Proctor (1990) in explicitly restricting their consideration of unimanual response data to only those conditions for which the responses were made at a neutral, midline location. However, more generally, their salient features coding account is neutral regarding which alternative is more salient, with the more fundamental points being that the stimulus and the response alternatives in orthogonal SRC tasks are coded asymmetrically and that response selection will benefit from the mapping in which the asymmetry structure of the stimulus set corresponds to that of the response set. To explain the response eccentricity effect, Weeks, Proctor, and Beyak (1995) hypothesized that when the response switch is not at midline and its location is, therefore, coded as left or right, the salience of the response code corresponding to the switch position is increased. When the switch position is coded as right, the right response becomes more salient, but when the switch position is coded as left, the left response becomes more salient.

Weeks et al. (1995) tested predictions of this hypothesis in two experiments. In Experiment 1, subjects made unimanual left-right switch movement responses to a vertically arrayed stimulus set. The major change from Michaels's (1989) and Michaels and Schilder's (1991) experiments was to remove the confound between responding hand and response location by having responses made at both contralateral and ipsilateral locations. The responses with each hand were made at five different locations: body midline and 15 or $30 \mathrm{~cm}$ to the left or right of midline. An up-right/down-left advantage was found at the two right response locations, and an up-left/downright advantage was found at the two left response locations for both hands, irrespective of which hand responded. This outcome is important because, according to the salient features coding explanation of the response eccentricity effect, location of the response switch is the critical factor, whereas according to the ecological hypothesis, motor properties associated with hand position are crucial.

To verify their hypothesis that the response eccentricity effect is due to increased salience of the response code corresponding to the switch position, in Experiment 2 Weeks et al. (1995) varied the position of the response switch relative to an inactive switch. Responses were made at the body midline in all conditions, with an inactive switch placed on the left side of the active response switch in one condition and on the right side in another condition. The location of the active switch with respect to the subject was identical in both conditions, but its location relative to the inactive switch was different. When the active switch was located to the right of the inactive switch, a 20-msec up-right/down-left advantage occurred, but when it was located to the left, an 8-msec up-left/ down-right advantage occurred. Thus, Weeks et al.'s Experiment 2 confirmed the prediction of their hypothesis that a response eccentricity effect could be obtained with a centered response position solely by varying the location of a referent switch.

\section{The Hand Posture Effect}

There is evidence that hand posture also affects the orthogonal SRC effect for unimanual movement responses. In Michaels and Schilder's (1991) Experiment 3, the responses were left-right toggle-switch movements made at midline with a prone or supine hand posture. Left-hand responses showed a 15-msec up-right/down-left advantage in the prone posture and a 23-msec up-left/down-right advantage in the supine posture. Right-hand responses showed a 3-msec up-left/down-right advantage in the 
prone posture and a 7-msec up-right/down-left advantage in the supine posture. Michaels and Schilder interpreted these results as consistent with their view that the state of the action system determines the compatibility effect.

Although plausible explanations of the up-right/downleft advantage and the response eccentricity effect in terms of correspondence of asymmetric S-R codes have been developed, no explanation of the hand posture effect in similar terms has yet been offered. For a convincing case to be made that both the up-right/down-left advantage and the orthogonal SRC effects that vary with hand placements are due primarily to correspondence of asymmetric feature codes, it is necessary for a plausible explanation of the hand posture effect to be developed. In this paper, we describe and test a specific hypothesis, which we call the hand referent hypothesis, regarding how the effects of hand posture on orthogonal SRC can be explained in terms of correspondence of asymmetric stimulus and response codes. Specifically, we hypothesize that the hand posture effect reflects the contribution of an additional spatial code for the response, which is based on the body of the hand serving as a frame of reference.

Thus, the hand referent hypothesis adds two tenets to that of the correspondence of asymmetric codes for deriving predictions. The first is that response coding occurs with respect to multiple frames of reference, with performance reflecting the summed contributions of the codes. Evidence indicates that categorical spatial codes specify the relations between an object and referent positions (Kosslyn, 1994) and that location information can be coded with respect to a variety of referents (CarlsonRadvansky \& Irwin, 1993). These referents include the focus of attention (Umiltà \& Liotti, 1987), the fingertipto-wrist axis of the responding hand (Lippa, 1996), and the body midline (see Cho \& Proctor, in press), as well as external objects. In many tasks, multiple spatial codes are formed in parallel, with the overall effect on performance reflecting their summed contributions. As one example, Behrmann and Tipper (1999) summarized research on visual selective attention as demonstrating that "the mechanisms of selective attention can simultaneously gain access to internal representations of spatial information defined with respect to both location- and object-based frames of reference" (p. 83). In addition, the magnitude of the Simon effect, a benefit for spatially corresponding stimulus and response locations when stimulus location is irrelevant, reflects the joint effects of codes based on multiple reference points (e.g., Lamberts et al., 1992; Roswarski $\&$ Proctor, 1996). With respect to orthogonal SRC, the overall up-right/down-left advantage is usually overlaid not only on the response eccentricity effect (e.g., Michaels $\&$ Schilder, 1991), but also on frame-of-reference effects that allow the stimuli and the responses to be coded along parallel dimensions (Hommel \& Lippa, 1995; Lippa, 1996; Proctor \& Pick, 1999). These outcomes suggest that the effect that is due to asymmetric coding of left and right induced by the location of the response device, or to parallel coding enabled by a reference frame, sums with the effect that is due to the asymmetric code responsible for the overall up-right/down-left advantage.

The second of the new tenets is that one of the frames of reference used to code the location of the response switch is the body of the hand. When a subject grasps a toggle switch with the thumb and index finger of his or her right hand, the switch is to the left of the body of the hand in a prone position, but to the right in a supine position; when he or she grasps the switch in a similar manner with his or her left hand, the spatial relation between the switch and the hand is reversed. The location of an object typically is coded relative to other objects, and as was noted in the previous paragraph, anatomical features can provide a basis for coding. If the location of the response switch is coded as left or right relative to the body of the hand, effects of hand posture on orthogonal SRC would be expected because the location code switches between prone and supine hand postures. Since responses in choicereaction tasks are coded in terms of the location of the response device, and not the location of the effector used to operate the device (e.g., Riggio, Gawryszewski, \& Umiltà, 1986), coding would likely be in terms of switch location relative to the hand, rather than hand location relative to the switch. If switch location is coded relative to the hand, as hypothesized, this location code should affect the relative salience of the left and the right responses in a manner consistent with the previously obtained results. Moreover, this effect of hand posture should sum with that of response eccentricity if the hand referent hypothesis is correct, because the two effects reflect contributions of different location codes for the response switch, one with respect to the body of the hand and the other with respect to the switch's position in the horizontal plane.

\section{The Present Study}

We conducted two experiments with vertically arrayed stimuli and left-right unimanual responses to evaluate the hand referent hypothesis, according to which the hand posture effect on orthogonal RT can be attributed to the body of the hand's serving as a referent for a location code. In Experiment 1, response switch location and hand posture (prone vs. supine) were manipulated factorially to examine the relation between response eccentricity and hand posture effects on orthogonal SRC. Responses were made at three different locations (body midline and left and right sides of midline) in two hand postures (prone and supine). The hand referent hypothesis predicts that the eccentricity effect will sum with that of hand posture.

Another implication of the hand referent hypothesis was tested in Experiment 2. This test was accomplished by manipulating which fingers were used to grasp the switch, the thumb and the index finger (as in Experiment 1) or the ring and little fingers. Responses were made at the midline with prone and supine hand postures. If, in accordance with the hand referent hypothesis, the postural effects are a function of coding switch location relative to the body of the hand, the hand posture effect obtained when the switch is grasped between the thumb and the index finger should 
be reduced or reversed when it is grasped between the ring and the little fingers, because the switch location relative to the body of the hand is changed.

\section{EXPERIMENT 1}

Michaels and Schilder (1991) showed that response eccentricity affects orthogonal SRC when hand posture is the same at all response positions and that prone versus supine hand posture influences orthogonal SRC when responses are made at body midline. However, because they did not manipulate the two variables orthogonally, it is unclear whether the effects of the two variables are additive or interactive. Therefore, in Experiment 1, response location and hand posture were varied factorially. Subjects made unimanual left-right movement responses with a toggle switch to stimuli presented above or below a fixation point. Responses were made at three different locations (ipsilateral, centered at body midline, and contralateral) in a palm-up or palm-down posture with each hand.

According to the hand referent hypothesis, the response eccentricity effect is a function of coding the response switch as located in the left or the right hemispace, and the hand posture effect is a function of coding the response switch as located left or right relative to the body of the hand. Thus, this hypothesis predicts that the response eccentricity effect on orthogonal SRC should be similar for the supine and the prone postures and that, for each hand, the pattern of hand posture effects should conform to that expected on the basis that the response opposite the body of the hand should be relatively more salient than the response in the direction of the body of the hand.

\section{Method}

Subjects. Forty-eight undergraduates enrolled in an introductory psychology course at Purdue University participated in partial fulfillment of a course requirement. All were right-handed and had normal or corrected-to-normal visual acuity as determined by selfreport. The subjects were randomly assigned to the two different hand posture groups: prone and supine.

Apparatus and Stimuli. The experiment was controlled by software developed with the Micro Experimental Laboratory 2 (MEL 2.0) system. The stimuli were presented on the display screen of an IBM-compatible microcomputer, and viewing distance was approximately $60 \mathrm{~cm}$. Responses were made by deflecting a toggle switch left or right in response to the spatial location of the imperative stimulus at three different locations: body midline and $30 \mathrm{~cm}$ to the left and right of midline. The toggle switch was mounted on a panel $(43 \times$ $17.5 \times 6 \mathrm{~cm}$ ) interfaced with a MEL 2 response box. The height of the toggle switch was $7.5 \mathrm{~cm}$.

The stimuli consisted of three rows of three asterisks $(0.9 \times$ $1.8 \mathrm{~cm}$, approximately $0.86^{\circ} \times 1.72^{\circ}$ of visual angle). They were presented as white characters on a dark background, $3.5 \mathrm{~cm}\left(3.34^{\circ}\right)$ above or below a fixation point that consisted of a row of purple asterisks $\left(0.9 \times 0.3 \mathrm{~cm}, 0.86^{\circ} \times 0.29^{\circ}\right)$ at the center of the screen.

Procedure. The subject was asked to align his or her body midline with the center of the screen and to place the hand with the palm

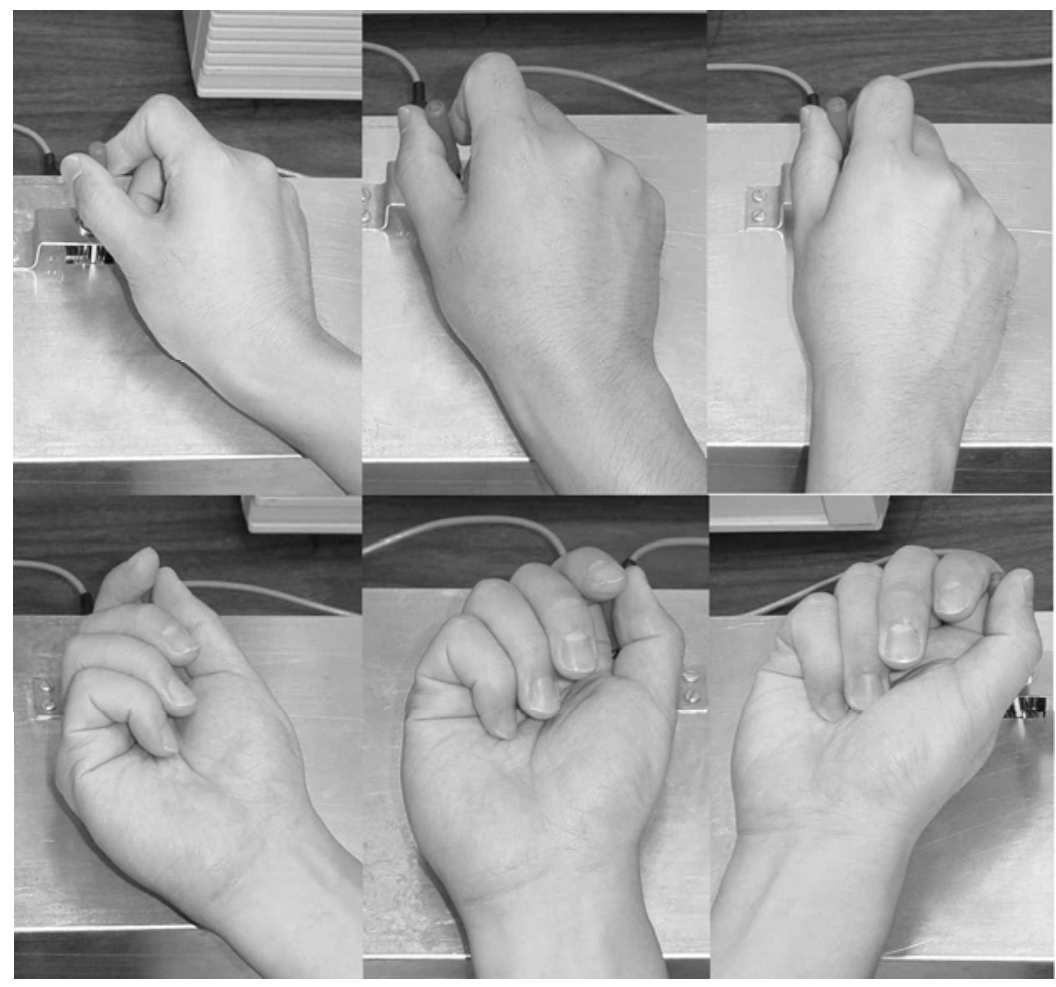

Figure 1. Hand postures used in Experiment 1, illustrated for the right hand. The top row shows the prone posture, and the bottom row shows the supine posture, in the left, center, and right response positions. 
Table 1

Mean Reaction Time (RT, in Milliseconds) and Percentage of Error (PE) in Experiment 1 as a Function of Mapping, Switch Location, Response Hand, and Hand Posture

\begin{tabular}{|c|c|c|c|c|c|c|c|}
\hline \multirow[b]{2}{*}{$\underline{\text { Hand }}$} & \multirow[b]{2}{*}{ Mapping } & \multicolumn{2}{|c|}{ Left } & \multicolumn{2}{|c|}{ Center } & \multicolumn{2}{|c|}{ Right } \\
\hline & & RT & $\mathrm{PE}$ & RT & $\mathrm{PE}$ & RT & $\mathrm{PE}$ \\
\hline \multicolumn{8}{|c|}{ Prone Posture } \\
\hline \multirow[t]{2}{*}{ Left } & Up-right/down-left & 386 & 4.29 & 379 & 2.61 & 363 & 0.84 \\
\hline & Up-left/down-right & 367 & 1.00 & 400 & 4.53 & 441 & 5.19 \\
\hline \multirow[t]{2}{*}{ Right } & Up-right/down-left & 426 & 4.79 & 378 & 1.67 & 367 & 0.59 \\
\hline & Up-left/down-right & 372 & 0.59 & 383 & 1.51 & 405 & 2.78 \\
\hline \multicolumn{8}{|c|}{ Supine Posture } \\
\hline \multirow[t]{2}{*}{ Left } & Up-right/down-left & 450 & 2.92 & 418 & 1.67 & 421 & 0.92 \\
\hline & Up-left/down-right & 403 & 0.33 & 416 & 1.78 & 459 & 3.73 \\
\hline \multirow[t]{2}{*}{ Right } & Up-right/down-left & 428 & 1.94 & 393 & 0.92 & 393 & 0.75 \\
\hline & Up-left/down-right & 430 & 1.86 & 441 & 3.53 & 476 & 4.27 \\
\hline
\end{tabular}

down in the prone condition and the palm up in the supine condition (see Figure 1). For both hand postures, the toggle switch was held between the thumb and the index finger, using the thumb to hold the switch against the finger between the knuckle and the fingertip. At the center position, the fingertip-to-wrist axis was approximately at a right angle to the left-right dimension for the response alternatives; at the left or right positions, the axis was angled so that the fingertips were rotated slightly in the direction corresponding to the response side (see Figure 1). The experiment consisted of 2 six-block sessions, with a 2-min rest period between them. Half of the subjects in each hand posture group performed the first session with the left hand and the second session with the right hand. The other half performed with the right hand first and then the left hand. Each session was comprised of 2 three-block phases, with a 2-min rest period between each phase. One mapping was used for the first phase, and the other was used for the second phase, with the order of the mappings counterbalanced across subjects. Half of the subjects began at the $30-\mathrm{cm}$ position in the right hemispace and progressed to the left. The other half began at the $30-\mathrm{cm}$ position in the left hemispace and progressed to the right. Each subject performed 10 practice trials in which a new or a different mapping was introduced, and each block consisted of 50 trials. After completing each block, a 30-sec rest period was given.

At the beginning of each trial, the fixation point was presented in the center of the screen for $500 \mathrm{msec}$. The imperative stimulus was presented above or below the fixation point, and both remained on until the subject responded. An incorrect response was followed by a 500-msec feedback tone. The fixation point for the next trial came on $1 \mathrm{sec}$ after the response or tone.

\section{Results}

RTs shorter than $125 \mathrm{msec}$ and longer than $1,250 \mathrm{msec}$ were removed as outliers, resulting in $0.48 \%$ of the trials being excluded. Mean RTs and percentages of error (PEs) were calculated for each subject as a function of mapping (up-right/down-left or up-left/down-right), response hand (left or right), and switch location (left, center, or right) as within-subject factors and hand posture (prone or supine) as a between-subjects factor (see Table 1). Analyses of variance (ANOVAs) were conducted on the mean RT and PE data.

Reaction time. RT was shorter with the prone posture $(M=389 \mathrm{msec})$ than with the supine posture $(M=$ $427 \mathrm{msec})$, as is indicated by a hand posture main effect $\left[F(1,46)=5.05, M S_{\mathrm{e}}=42,463, p=.029\right]$. RT also var- ied significantly as function of switch location $[F(2,92)=$ $\left.11.08, M S_{\mathrm{e}}=942, p<.0001\right]$, being shortest at the body midline $(M=401 \mathrm{msec})$, intermediate at the left location $(M=408 \mathrm{msec})$, and longest at the right location $(M=$ $416 \mathrm{msec})$. This effect of switch location did not interact with hand posture $\left[F(2,92)=1.66, M S_{\mathrm{e}}=942, p=.196\right]$.

Response hand interacted with switch location $[F(2,92)=$ 9.05, $\left.M S_{\mathrm{e}}=747, p=.0003\right]$, and these two variables entered into a three-way interaction with hand posture $[F(2,92)=$ $\left.4.68, M S_{\mathrm{e}}=747, p=.012\right]$. Right-hand responses were fastest at the body midline $(M \mathrm{~s}=399,414$, and $410 \mathrm{msec}$ for midline, left, and right switch locations, respectively), and left-hand responses were fastest at the midline and left locations $(M \mathrm{~s}=403,402$, and $420 \mathrm{msec}$ for midline, left, and right switch locations, respectively). With the prone hand posture, responses were faster at the ipsilateral location than at the contralateral location, but with the supine posture, they were fastest at the body midline and slowest at the right switch location.

The outcomes of primary concern involve the mapping effect (see Figure 2). An overall up-right/down-left advantage was obtained, with RTs shorter for the up-right/ down-left mapping $(M=400 \mathrm{msec})$ than for the up-left/ down-right mapping $[M=416 \mathrm{msec} ; F(1,46)=13.63$, $\left.M S_{\mathrm{e}}=2,648, p=.0006\right]$. The magnitude of the up-right/ down-left advantage was $11 \mathrm{msec}$ with the prone hand posture and $20 \mathrm{msec}$ with the supine hand posture, but the interaction between mapping and hand posture was not significant $\left[F(1,46)=1.07, M S_{\mathrm{e}}=2,648, p>.30\right]$. The three-way mapping $\times$ hand posture $\times$ response hand interaction was significant $\left[F(1,46)=22.76, M S_{\mathrm{e}}=2,414\right.$, $p<.0001]$, but these variables did not enter into a higher order interaction with switch location $[F(2,92)<1]$. The effect of hand posture on the orthogonal SRC effect was opposite for the two hands (see Figure 3): The right hand showed a 4-msec up-left/down-right advantage in the prone posture and a 44-msec up-right/down-left advantage in the supine posture, whereas the left hand showed a 27-msec up-right/down-left advantage in the prone posture and a 4-msec up-left/down-right advantage in the supine posture. 

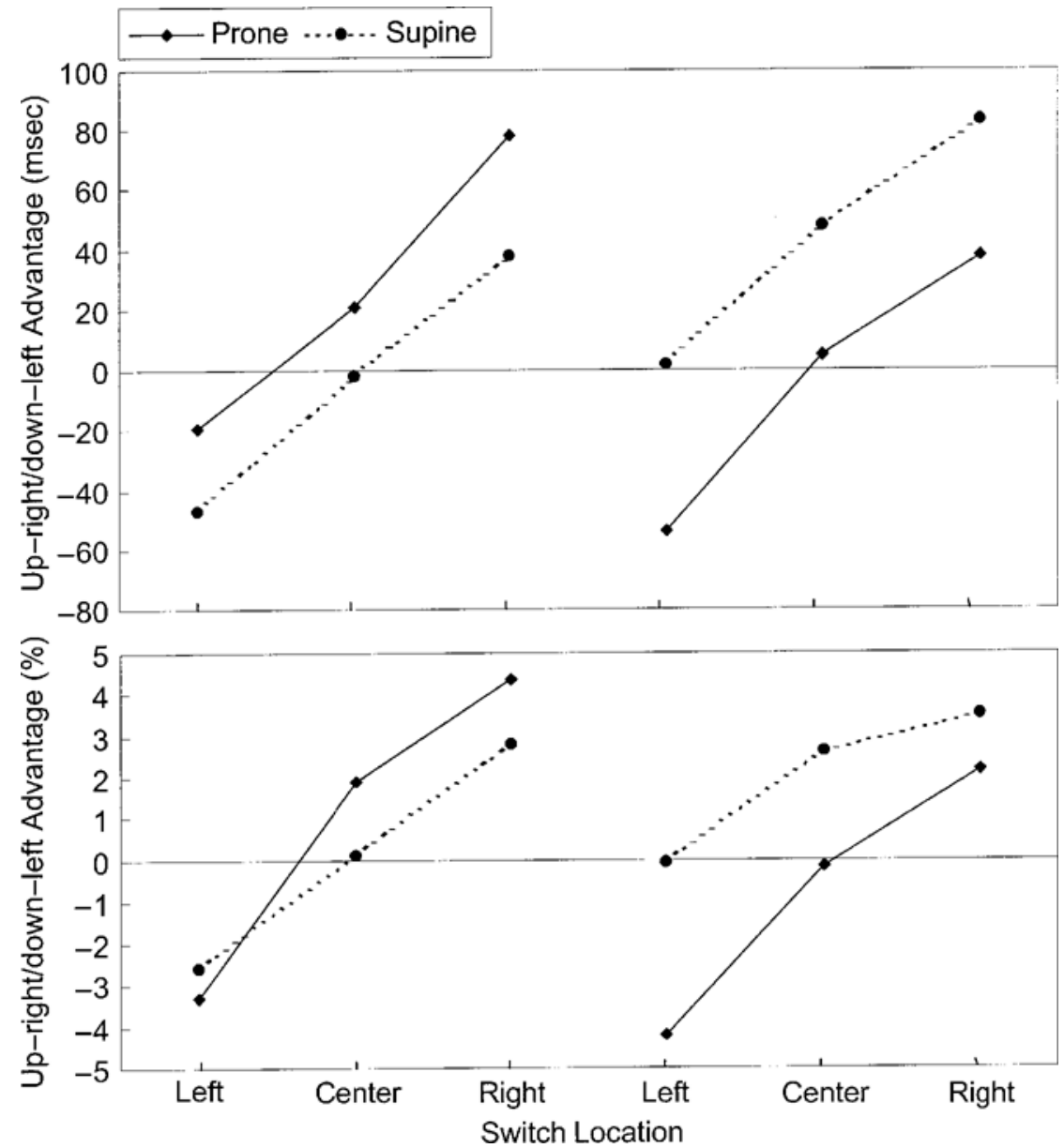

Figure 2. The up-right/down-left advantage as a function of switch location and hand posture for reaction time and percentage of error in Experiment 1.

A response eccentricity effect was found, as is indicated by a mapping $\times$ switch location interaction $[F(2,92)=$ 94.87, $\left.M S_{\mathrm{e}}=966, p<.0001\right]$. The up-right/down-left advantage of $18 \mathrm{msec}$ at midline increased to $59 \mathrm{msec}$ at the right switch location and reversed to $-29 \mathrm{msec}$ at the left switch location. Most important, no higher order interactions of the mapping and switch location with response hand and hand posture were significant $\left[F_{\mathrm{s}}(2,92)<1\right]$, indicating that the response eccentricity effect was similar across hands and postures (see Figure 2).

Percentage of error. Overall PE was $2.29 \%$, and PEs for the two hand postures were not significantly different $\left[F(1,46)=1.59, M S_{\mathrm{e}}=20.97, p=.214\right]$. More errors were made when responding with the left hand ( $\mathrm{PE}=$ $2.48 \%)$ than with the right hand $(\mathrm{PE}=2.10 \%)$, but this difference was not significant $\left[F(1,46)=3.16, M S_{\mathrm{e}}=\right.$ $6.72, p=.082]$. The interaction between response hand and posture was significant $\left[F(1,46)=10.62, M S_{\mathrm{e}}=20.97\right.$, $p=.002]$. With the prone posture, responses were more accurate with the right hand $(\mathrm{PE}=1.99 \%)$ than with the left hand $(\mathrm{PE}=3.08 \%)$, but with the supine posture, responses were more accurate with the left hand ( $\mathrm{PE}=$ $1.89 \%)$ than with the right hand ( $\mathrm{PE}=2.21 \%)$. Response hand and posture interacted with switch location $[F(2,92)=$ $\left.3.75, M S_{\mathrm{e}}=4.09, p=.027\right]$. As for the RT data, responses were more accurate at the ipsilateral location than at the contralateral location with the prone posture but were more accurate at the left switch location than at the right switch location for both hands with the supine posture.

The PE data also showed a $0.6 \%$ up-right/down-left advantage $\left[F(1,46)=4.65, M S_{\mathrm{e}}=11.09, p=.0362\right]$. This mapping effect did not interact with hand posture $[F(1,46)=$ $\left.2.80, M S_{\mathrm{e}}=11.09, p=.101\right]$ or response hand $[F(1,46)<$ 1]. However, the three-way mapping $\times$ hand posture $\times$ response hand interaction was significant $[F(1,46)=18.09$, $M S_{\mathrm{e}}=6.53, p<.0001 ;$ see Figure 3]. The right hand showed a $0.73 \%$ up-left/down-right advantage in the prone posture and a $2.02 \%$ up-right/ down-left advantage in the supine posture, whereas the left hand showed a $0.99 \%$ up-right/down-left advantage in the prone posture 

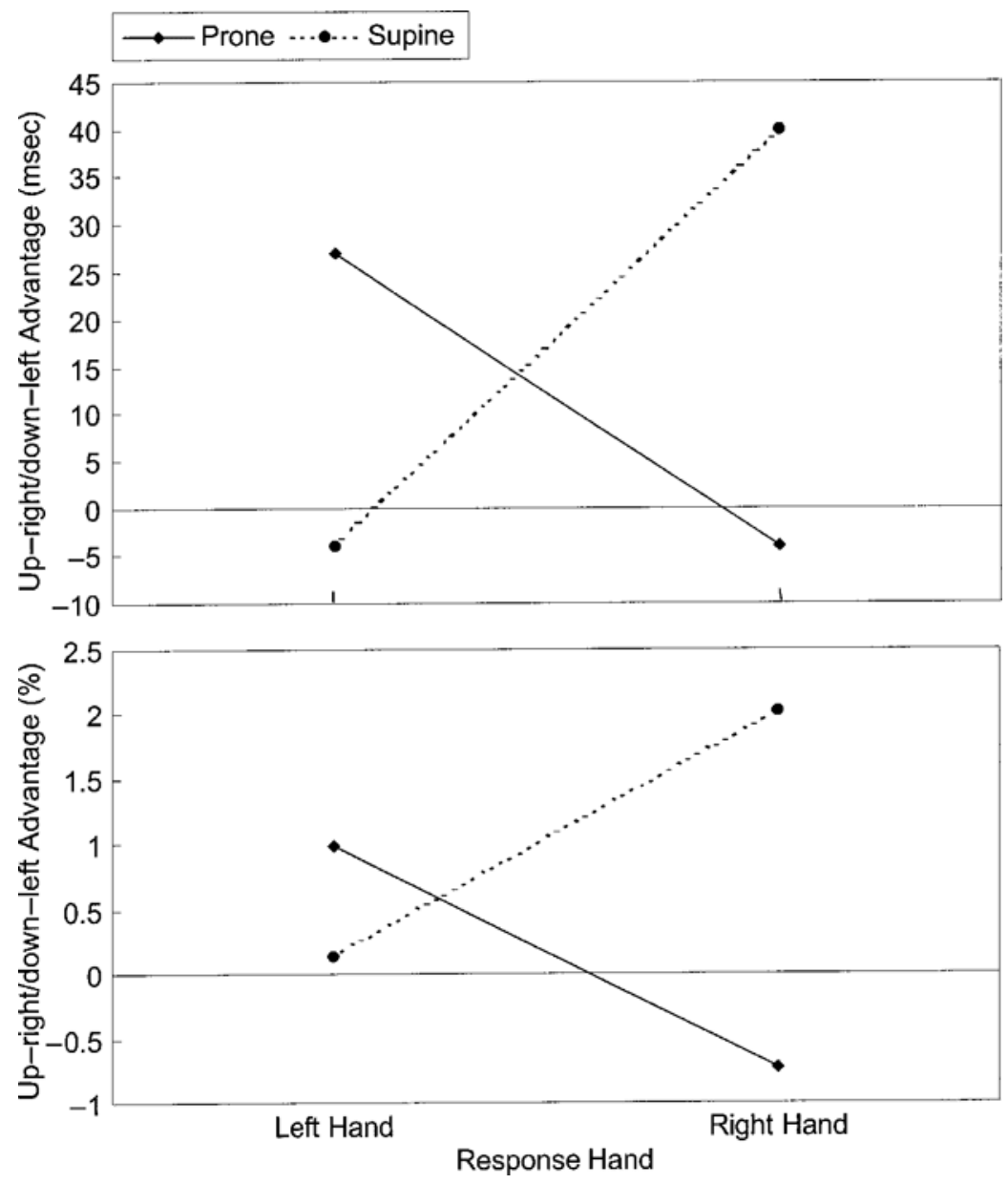

Figure 3. The up-right/down-left advantage as a function of hand posture and response hand for reaction time and percentage of error in Experiment 1.

that was reduced to $0.11 \%$ in the supine posture. The only difference from the RT data is that this last value did not switch direction to an up-left/down-right advantage.

Mapping also interacted with switch location $[F(2,92)=$ $\left.49.67, M S_{\mathrm{e}}=8.21, p<.0001\right]$, showing a response eccentricity effect similar to the RT data (see Figure 2). The up-right/down-left advantage was $3.22 \%$ at the right switch location, $1.11 \%$ at body midline, and $-2.55 \%$ at the left switch location. This eccentricity effect did not interact significantly with hand posture $[F(2,92)=2.54$, $\left.M S_{\mathrm{e}}=8.21, p=.084\right]$, response hand $[F(2,92)=1.36$, $\left.M S_{\mathrm{e}}=5.21, p=.263\right]$, or both $[F(2,92)<1.0]$.

\section{Discussion}

An overall up-right/down-left advantage was apparent in both the RT and the PE data, in agreement with the point made in the introduction that an up-right/down-left advantage is often apparent in the overall data for the type of orthogonal SRC effect that is influenced by response eccentricity. As in Weeks et al.'s (1995) Experiment 1, the mapping preference was influenced by response eccen- tricity: The up-right/down-left advantage found when the switch was placed at the body midline was increased when the switch was in the right hemispace and was reversed when it was in the left hemispace, regardless of response hand. The magnitudes of the response eccentricity effect for the left-hand (91 $\mathrm{msec}$ and $6.51 \%$ ) and the right-hand (86 msec and $5.01 \%$ ) responses were similar to each other. This pattern replicates that of Weeks et al.'s Experiment 1.

As in Michaels and Schilder's (1991) Experiment 3, hand posture affected orthogonal SRC. When responses were made with the left hand, the up-right/down-left advantage was evident overall with the prone posture, and little difference was shown with the supine posture. In contrast, when responses were made with the right hand, the up-right/down-left advantage was evident with the supine posture, and little difference was evident with the prone posture. In Michaels and Schilder's experiment, the right-hand responses showed no mapping preference, whereas the left-hand responses showed the up-right/ down-left advantage in the prone condition and the up-left/down-right advantage in the supine condition. 
Despite this minor difference, the overall pattern of hand posture effects on orthogonal SRC was similar in Michaels and Schilder's and the present experiments.

Although both response eccentricity and hand posture affected orthogonal SRC, their effects did not interact significantly. For both prone and supine hand postures, the up-right/down-left advantage found at body midline increased in the right hemispace and reversed in the left hemispace, as would be expected on the basis of Weeks et al.'s (1995) hypothesis that the location of the response switch is coded with respect to the hemispace in which the switch is placed. Independent of this effect of response eccentricity, the up-right/down-left advantage was larger for the hand postures in which the switch was to the right relative to the body of the hand than for those in which it was to the left. This pattern of additive effects is in agreement with the hypothesis that the response switch is also coded with respect to the body of the hand. More generally, the overall result pattern conforms to the view that codes are formed relative to the available frames of reference, with RT reflecting their summed contributions (e.g., Lamberts et al., 1992; Lippa, 1996; Proctor \& Pick, 1999).

\section{EXPERIMENT 2}

Experiment 2 provided an additional test of the hand referent hypothesis. Subjects made unimanual left-right switch movements in response to stimuli presented above or below a fixation point at the body midline in prone and supine hand postures. To examine the effect of the spatial relation between the response switch and the responding hand, the grasping method was manipulated. The subjects grasped the toggle switch with their thumb and index finger in one condition (as in Experiment 1) and with their ring and little fingers in the other. The idea behind this manipulation was that the spatial relations between the switch and the body of the responding hand change between the two types of grasp. For example, with the right hand in a prone posture, the response switch is to the left of the body of the hand when the switch is grasped between the thumb and the index finger. However, when the switch is grasped between the ring and the little fingers, the response switch is to the right relative to the main body of the hand, although this relation is less pronounced because the little finger is part of the main body of the hand, whereas the opposable thumb is a separate appendage.

If the location of the response switch is coded relative to the body of the responding hand, the effect of hand posture found in Experiment 1 and in Michaels and Schilder's (1991) Experiment 3 when the switch was grasped with the thumb and the index finger should change systematically when the switch is grasped with the ring and the little fingers. For example, with the right hand in the prone posture, the up-left/down-right mapping advantage with the thumb-index grasp should shift toward an increased preference for the up-right/down-left mapping with the ring-little grasp. This is because the position of the switch relative to the body of the hand is left for the thumb-index grasp but right with the ring-little grasp. If as was noted above, the coding of switch location relative to hand is more ambiguous with the ring-little grasp than with the thumb-index grasp, the relative advantages for the alternative mappings will not reverse completely for the ring-little grasp but will only shift in the direction of a reduction in the mapping advantage evident with the thumb-index grasp.

\section{Method}

Subjects. Forty-eight undergraduate students from the same pool as that in Experiment 1 participated in partial fulfillment of a course requirement. None of the subjects took part in the previous experiment, and all were right-handed and had normal or corrected-tonormal visual acuity as determined by self-report. The subjects were randomly assigned to the two different hand posture conditions: prone and supine.

Apparatus, Stimuli, and Procedure. The apparatus and stimuli were similar to those in Experiment 1, except that only the body midline position for the response switch was used. The switch was placed on the table, in an upright position. The subjects in the prone posture group were instructed to grasp the toggle switch with the palm down, and the subjects in the supine posture group were instructed to grasp the toggle switch with the palm up (see Figure 4).

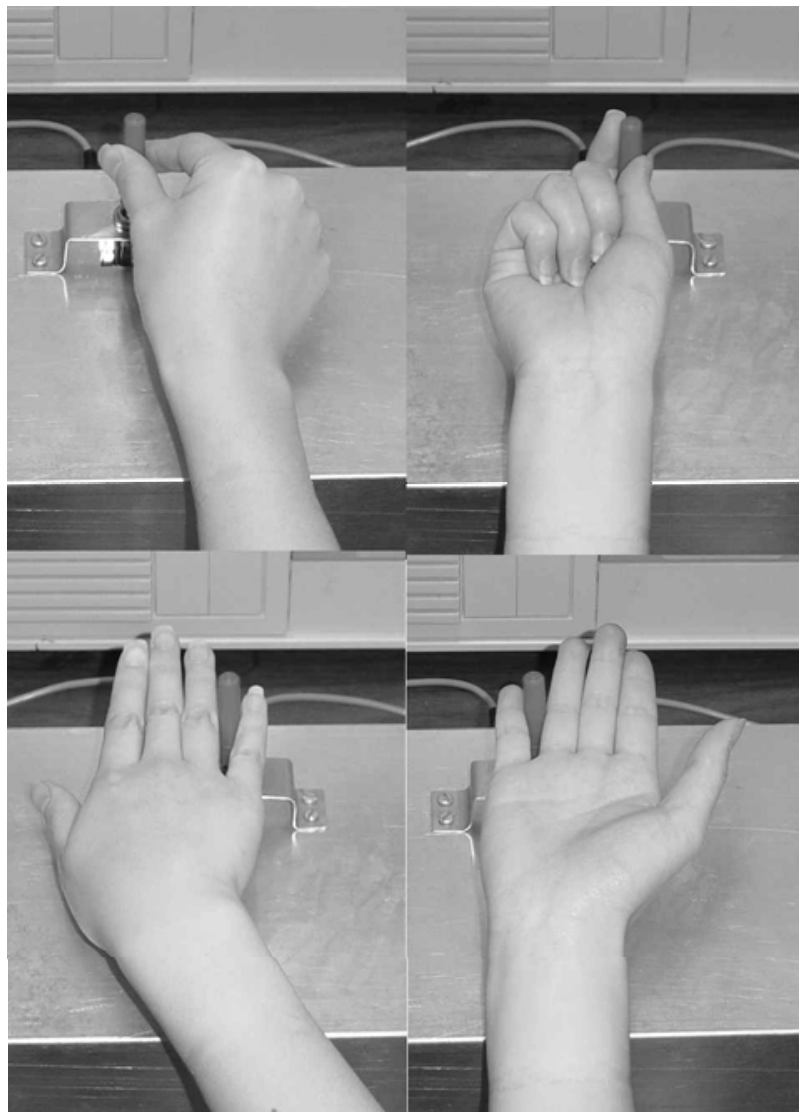

Figure 4. Hand postures used in Experiment 2, illustrated for the right hand. The left column shows the prone posture, and the right column shows the supine posture, with the thumb-index and ring-little grasps. 
The fingertip-to-wrist axis was approximately at a right angle relative to the left-right response dimension.

The experiment consisted of 2 four-block sessions, with a 30 -sec rest period between blocks and a 2-min rest period between sessions. In each hand posture condition, half of the subjects performed with the up-right/down-left mapping in the first session and the up-left/down-right mapping in the second session. The other half performed with the mappings in the reverse order. Within a session, half of the subjects performed with the right hand in the first two blocks of each session and the left hand in the last two blocks, whereas the other half performed with the left hand first. For one block in each pair, the switch was grasped between the thumb and the index finger (the thumb-index grasp), and for the other, the switch was grasped between the ring and the little fingers (the ring-little grasp). The order of grasping method was counterbalanced across the subjects. The thumb-index grasp was the same as that in Experiment 1; for the ring-little grasp, the little finger pressed the switch against the ring finger at approximately the knuckle.

\section{Results}

A total of $0.36 \%$ of the trials was removed from analysis for having RTs shorter than $125 \mathrm{msec}$ or longer than 1,250 msec. Mean RTs and PEs were calculated for each subject as a function of mapping (up-right/down-left and up-left/down-right), response hand (left and right), and grasping method (thumb-index and ring-little grasps) as within-subjects factors and hand posture as a betweensubjects factor (see Table 2). Analyses of variance were conducted on the mean RT and PE data.

Reaction time. Although RTs tended to be shorter with the prone posture $(M=388 \mathrm{msec})$ than with the supine posture $(M=405 \mathrm{msec})$, the hand posture main effect was not significant $\left[F(1,46)=2.18, M S_{\mathrm{e}}=12,666\right.$, $p=.1465]$. The only significant term not involving the mapping variable was response hand $\times$ hand posture $\times$ grasping method $\left[F(1,46)=4.14, M S_{\mathrm{e}}=422, p=.0476\right]$. For the right hand, the mean RT was $7.5 \mathrm{msec}$ shorter with the ring-little grasp than with the thumb-index grasp in both hand postures. But for the left hand, the ring-little grasp was $17 \mathrm{msec}$ faster than the thumb-index grasp in the supine posture, with the thumb-index grasp being $2 \mathrm{msec}$ faster than the ring-little grasp in the prone posture.
There was no overall advantage for either mapping $[F(1,46)<1]$, but as in Experiment 1, the three-way mapping $\times$ response hand $\times$ hand posture interaction was significant $\left[F(1,46)=18.72, M S_{\mathrm{e}}=1,193, p<.0001\right]$. For the right hand, a 12-msec up-left/down-right advantage was found in the prone posture, and a 31-msec up-right/ down-left advantage was found in the supine posture, but for the left hand, this was reversed to a 4-msec up-right/ down-left advantage in the prone posture and a 15-msec up-left/down-right advantage in the supine posture. The two-way interactions of mapping with hand posture $\left[F(1,46)=4.47, M S_{\mathrm{e}}=729, p=.0400\right]$ and response hand $\left[F(1,46)=4.38, M S_{\mathrm{e}}=1,193, p=.0419\right]$ were significant. These two interactions reflect the fact that the conditions producing an up-left/down-right advantage yielded effects of similar magnitude $(12 \mathrm{msec}$ for the right hand in the prone posture and $15 \mathrm{msec}$ for the left hand in the supine posture), but those producing an up-right/ down-left advantage yielded effects of different magnitudes (31 msec for the right hand in the supine posture and $4 \mathrm{msec}$ for the left hand in the prone posture).

Most important, the four-way mapping $\times$ response hand $\times$ hand posture $\times$ grasping method interaction was also significant $\left[F(1,46)=4.95, M S_{\mathrm{e}}=622, p=.0311\right]$. Although the three-way mapping $X$ response hand $X$ hand posture interaction was significant for both the thumb-index grasp $[F(1,46)=33.77, p<.0001]$ and the ring-little grasp $[F(1,46)=7.11, p=.0106]$, the pattern of results showed that orthogonal SRC was influenced by the location of the switch relative to the response hand (see Figure 5). When the switch was placed between the ring and the little fingers, the dependence of the mapping effect on response hand and hand posture decreased. Specifically, with the right hand, when responses were made in the prone posture, a 19-msec up-left/down-right advantage was found with the thumb-index grasp (for which the switch was left relative to the hand) and a 4-msec up-left/down-right advantage was found with the ring-little grasp (for which the switch was right relative to the hand); when responses were made in the supine posture, a 39-msec up-right/down-left advantage was found

Table 2

Mean Reaction Time (RT, in Milliseconds) and Percentage of Error (PE) in Experiment 2 as a Function of Mapping, Grasping Method, Response Hand, and Hand Posture

\begin{tabular}{|c|c|c|c|c|c|}
\hline \multirow[b]{2}{*}{ Hand } & \multirow[b]{2}{*}{ Mapping } & \multicolumn{2}{|c|}{ Thumb-Index Grasp } & \multicolumn{2}{|c|}{ Ring-Little Grasp } \\
\hline & & RT & $\mathrm{PE}$ & RT & PE \\
\hline \multicolumn{6}{|c|}{ Prone Posture } \\
\hline \multirow[t]{2}{*}{ Left } & Up-right/down-left & 383 & 1.42 & 391 & 2.25 \\
\hline & Up-left/down-right & 393 & 1.64 & 389 & 1.66 \\
\hline \multirow{2}{*}{ Right } & Up-right/down-left & 400 & 2.67 & 385 & 2.16 \\
\hline & Up-left/down-right & 381 & 1.17 & 381 & 2.01 \\
\hline \multicolumn{6}{|c|}{ Supine Posture } \\
\hline \multirow[t]{2}{*}{ Left } & Up-right/down-left & 415 & 3.18 & 397 & 1.92 \\
\hline & Up-left/down-right & 398 & 0.49 & 384 & 0.82 \\
\hline \multirow[t]{2}{*}{ Right } & Up-right/down-left & 396 & 1.58 & 396 & 1.41 \\
\hline & Up-left/down-right & 435 & 2.85 & 419 & 2.51 \\
\hline
\end{tabular}



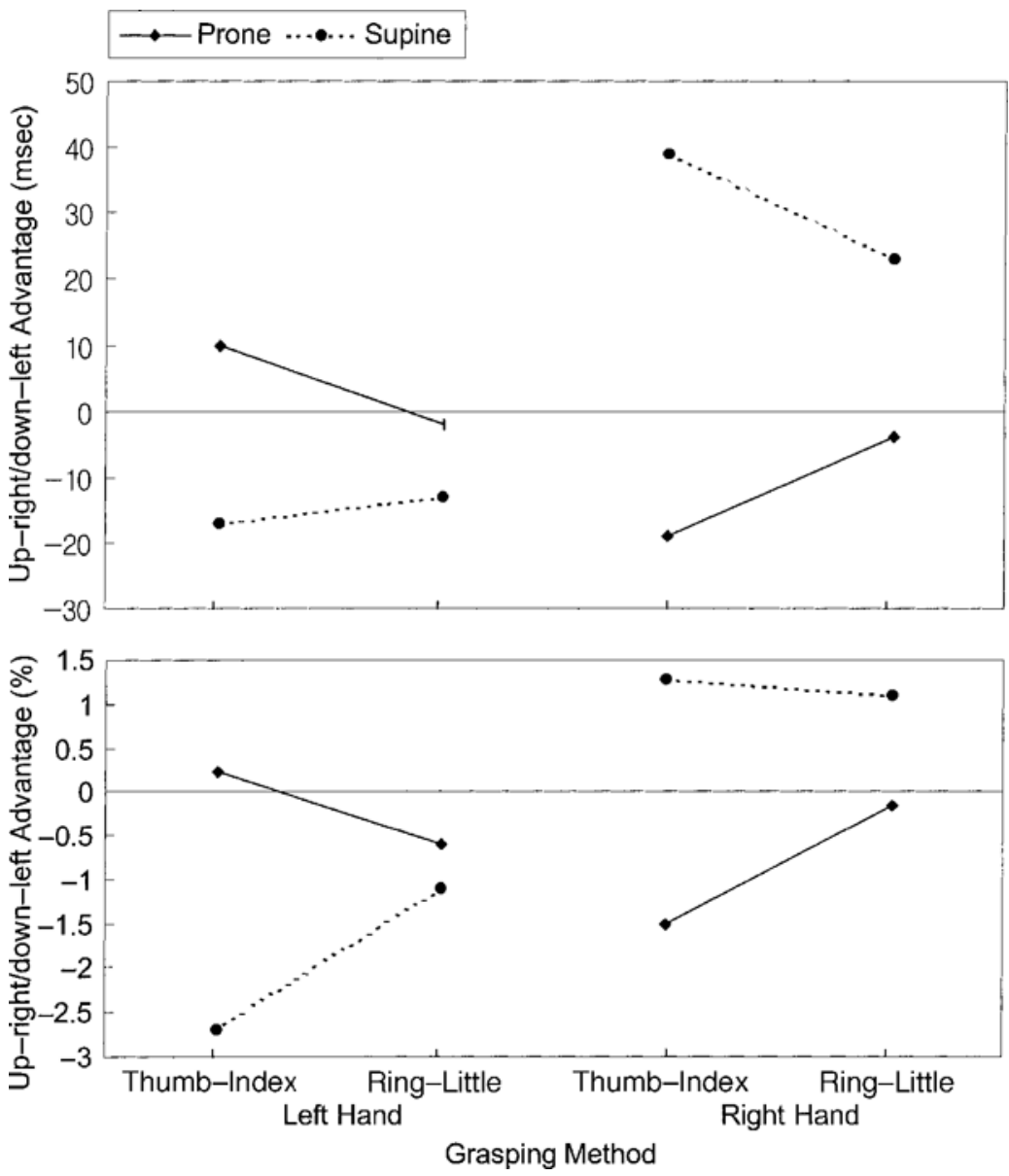

Figure 5. The up-right/down-left advantage as a function of hand posture and grasping method for reaction time and percentage of error in Experiment 2.

with the thumb-index grasp and a 23-msec up-right/ down-left advantage was found with the ring-little grasp. With the left hand, when responses were made in the prone posture, a 10-msec up-right/down-left advantage occurred with the thumb-index grasp, and a 2-msec up-left/down-right advantage occurred with the ringlittle grasp; when responses were made in the supine posture, a 17 -msec up-left/down-right advantage was found with the thumb-index grasp and a 13-msec up-left/downright advantage was found with the ring-little grasp.

Percentage of error. Overall PE was $1.86 \%$. None of the main effects was significant, and the only significant two-way interaction was response hand $\times$ mapping $\left[F(1,46)=5.35, M S_{\mathrm{e}}=6.58, p=.0253\right]$. The right hand showed a $0.17 \%$ up-right/down-left advantage, whereas the left hand showed a $1.03 \%$ up-left/down-right advantage. Response hand and mapping also interacted with hand posture $\left[F(1,46)=12.58, M S_{\mathrm{e}}=6.58, p=.0009\right]$. When responses were made in the prone posture, the right- and left-hand responses showed up-left/down-right advantages of $0.83 \%$ and $0.19 \%$, respectively. However, when responses were made in the supine posture, the right-hand responses showed a $1.18 \%$ up-right/down-left advantage, and the left-hand responses showed a $1.9 \%$ up-left/down-right advantage. As for the RT data, this pattern differed systematically with the grasping method (see Figure 5), but it did not reach statistical significance $\left[F(1,46)=2.94, M S_{\mathrm{e}}=7.82, p=.0934\right]$. With the thumbindex grasp, errors were fewer for the up-right/ down-left mapping than for the other mapping with the left hand in the prone posture and with the right hand in the supine posture but were more numerous with the left hand in the supine posture and the right hand in the prone posture. All of these differences were reduced or reversed with the ring-little grasp.

\section{Discussion}

As is predicted by the hand referent hypothesis, the effects of hand posture on orthogonal SRC varied systematically as a function of whether the switch was grasped between the ring and the little fingers or between the thumb and the index finger. The mapping advantages found with 
the thumb-index grasp were reduced in magnitude when the toggle switch was grasped with the ring and little fingers. In all cases, the shift was in the direction that would be expected if the switch were spatially coded relative to the body of the hand, influencing the relative salience of the response alternatives.

Although grasping method affected orthogonal SRC in the manner predicted by the hand referent hypothesis, the pattern of results obtained with the thumb-index grasp was reduced but not reversed by the change to the ringlittle grasp. As was noted in the introduction to Experiment 2 , this result would occur if the left or the right position of the switch relative to the hand is more distinct when the switch is grasped by the thumb and the index finger than when grasped by the ring and the little fingers. A likely basis for this difference in distinctiveness is that the thumb is separate from the four other fingers and is not part of the body of the hand. With the thumb-index grasp, the four fingers are aligned to one side of the switch, whereas with the ring-little grasp, three fingers are to one side of the switch and one finger to the other side. Consequently, the left or the right position of the switch relative to the hand is more distinct when grasped between the thumb and the index finger.

Also, independent of grasping method, the up-right/ down-left advantage was much larger for the right hand in the supine posture $(31 \mathrm{msec})$ than for the left hand in the prone posture $(4 \mathrm{msec})$, although there was little difference in the magnitude of the up-left/down-right advantage between the left hand in the supine posture $(15 \mathrm{msec})$ and the right hand in the prone posture $(12 \mathrm{msec})$. It is not clear, however, whether this large SRC effect for the right hand in the supine posture is a reliable phenomenon. The tendency for the right hand in the supine posture to show a large up-right/down-left advantage was nonsignificant in Experiment 1, and the up-right/down-left advantage for the right hand was smaller $(7 \mathrm{msec})$ than the up-left/ down-right advantage $(23 \mathrm{msec})$ for the left hand in Michaels and Schilder's (1991) Experiment 3. If the residual effect for the right hand in a supine posture, evident in Experiment 2, turns out to be reliable, the salient features coding perspective does not provide an obvious explanation for it, but neither does the ecological perspective or the end-state comfort hypothesis.

\section{GENERAL DISCUSSION}

Lippa and Adam (2001) distinguished two types of orthogonal SRC effects. The first is an overall up-right/ down-left mapping advantage for which the only viable account currently is that of salient features coding: Up and right tend to be coded as the salient poles of their dimensions, and response selection is more efficient with the up-right/down-left mapping than with the alternative mapping because it directly maps the salience relation of the stimuli onto that of the responses (Weeks \& Proctor, 1990). The only disagreement is whether asymmetric coding of this type is restricted to verbal codes (Adam et al.,
1998) or occurs more generally for spatial coding, as Weeks and Proctor originally proposed, and the evidence favors the view that asymmetry is a general coding property (Cho \& Proctor, 2001, in press; Proctor \& Cho, 2001).

The second type of orthogonal SRC effect is obtained with unimanual responses and varies as a function of response eccentricity and hand posture. Weeks et al. (1995) showed that the salient features coding perspective can provide an adequate explanation of the response eccentricity effect on orthogonal SRC. According to this account, the mapping preference changes across response locations are a function of the response apparatus's being coded as left or right, with the response corresponding to to the location of the apparatus increasing in salience, relative to the alternative response code. These prior studies thus made the points that (1) the stimulus and the response alternatives are coded asymmetrically and the mapping that maintains the asymmetry of the stimulus set in the response set leads to better performance than does the one that does not and (2) with unimanual responses, the response code consistent with the relative location code for the location of the response apparatus is relatively more salient than the one that is not.

\section{The Hand Referent Hypothesis}

No prior attempt has been made to explain the hand posture effect on orthogonal SRC in terms of asymmetric coding, and this effect seems, on the surface, to be more consistent with the accounts that emphasize properties of the motor system (Lippa \& Adam, 2001; Michaels \& Schilder, 1991). The present experiments were designed to test a hypothesis for explaining the hand posture effect that is consistent with the salient features coding perspective. The general idea is that this effect is similar to the response eccentricity effect in that both reflect the influence of distinct relative location codes for the response apparatus. According to this hand referent hypothesis, the hand posture effect arises from the fact that the switch is located to one side or the other of the body of the hand. Consequently, the switch is coded left or right relative to the hand; as with the response eccentricity effect, coding the switch as right relative to the hand increases the salience of the right response, and coding the switch as left increases the salience of the left response. Because the location codes with reference to the hand are distinct from those with respect to hemispace, the effects of hand posture and response eccentricity on orthogonal SRC should sum.

Previous studies have manipulated hand posture only at the midline position. In Experiment 1, subjects performed with prone or supine hand postures at ipsilateral, midline, and contralateral locations for both the left and the right hands. The results showed effects of response eccentricity and prone-supine hand posture on orthogonal SRC. The response eccentricity effect occurred regardless of whether the left or the right hand was used for responding and, most important, whether the hand was placed in a prone or a supine posture. The eccentricity and posture effects did not interact significantly, with the hand posture effect 
being similar to that obtained by Michaels and Schilder (1991) at the midline location: Averaged across response locations, in the prone posture, an up-right/down-left advantage was evident for the left hand, and an up-left/ down-right advantage was evident for the right hand; in the supine posture, these advantages were opposite. This effect of hand posture is the pattern expected if the body of the hand is serving as a frame of reference, as hypothesized. The independence of the response eccentricity effect from responding hand provides confirmation of Weeks et al.'s (1995) finding that the response location, rather than the hand, is the primary determinant of the response eccentricity effect.

In Experiment 2, the grasping method was manipulated to vary the location of the toggle switch relative to the responding hand. By varying whether the switch was grasped between the thumb and the index finger, as is normal, or between the little and the ring fingers, it was possible to vary the position of the response switch relative to the body of the hand separately from the manipulation of hand posture. For both left and right hands in prone and supine postures, the hand posture effect on orthogonal SRC found when the switch was grasped with the thumb and the index finger decreased in magnitude when the switch was grasped with the ring and the little fingers. This effect of grasping method on orthogonal SRC is in agreement with predictions of the hand referent hypothesis, assuming that the position of the switch relative to the hand is more obviously left or right with the thumb-index grasp than with the ring-little grasp. More generally, the influence of grasping method is consistent with the emphasis of the salient features coding perspective on relative location coding and the view that multiple spatial codes are formed with respect to various referents (e.g., Cho \& Proctor, in press; Ehrenstein, Schroeder-Heister, \& Heister, 1989; Proctor \& Pick, 1999).

\section{The End-State Comfort Hypothesis}

The primary alternative explanation for the response eccentricity and hand posture effects on orthogonal SRC is Lippa and Adam's (2001) end-state comfort hypothesis. According to this hypothesis, the hand posture establishes movement constraints that determine the direction of spatial transformation for mentally aligning the response dimension with the stimulus dimension. It is the specific mental alignment of the response dimension with the stimulus dimension for a particular response situation that determines which mapping will be compatible and which incompatible: If the horizontal response dimension is rotated counterclockwise, the up-right/down-left mapping will be most compatible, whereas if it is rotated clockwise, the up-left/down-right mapping will be most compatible.

Lippa and Adam (2001) noted the following for the account of orthogonal SRC effects provided by the end-state comfort hypothesis:

Orthogonal SRC effects that vary with hand or response position are not attributed to hand or response location alone, but are attributed to the interplay of these variables: It is hand posture relative to the response device and the body that constrains imagined hand movements and response transformations, thereby evoking compatibility effects. (p. 172)

The results of Experiment 1, which show that the influence of response eccentricity on orthogonal SRC effects is not moderated by hand posture, provide little support for the view that hand posture evokes the compatibility effects. If it is assumed that the most comfortable rotation direction for the hand-arm system determines whether the response dimension is mentally rotated clockwise or counterclockwise, it is possible to argue that the direction of mental rotation would be the same for the supine and the prone hand postures. However, such an account would seem to predict no influence of hand posture on orthogonal SRC, contrary to the results of Experiments 1 and 2. The finding in Experiment 2, that systematic changes in the pattern of orthogonal SRC effects occur as a function of grasping method (thumb-index or ring-little), creates additional difficulty for the end-state comfort hypothesis, because the rotational constraints seem to be similar for the two grasping methods. In sum, as currently developed, the end-state comfort hypothesis does not seem able to account for the results of either experiment.

Lippa and Adam (2001, Experiment 4) reported a hand posture effect on orthogonal SRC when the responses were keypresses that they interpreted as consistent with the end-state comfort hypothesis. In their experiment, subjects held a computer mouse attached at the front of a chinrest with the left or the right hand and made unimanual left-right keypresses with the index and the middle fingers to a vertically arrayed stimulus set. They held the hand in one of two postures, facing the back of the hand (prone) or the palm (supine). The "left" and "right" keys were defined in terms of the body midline. The general pattern of results for that experiment was similar to those obtained in the present Experiments 1 and 2 and in Michaels and Schilder's (1991) Experiment 3 for unimanual switch movements in the transverse plane: The right and the left hands showed different mapping preferences in the prone posture, and these preferences reversed in the supine posture.

Although a change in hand posture reversed the mapping preferences in Lippa and Adam's (2001) experiment, as in the other studies in which hand posture was varied, the mapping preferences in their experiment were opposite those of the other studies: The results showed an up-right/down-left advantage with the right hand and an up-left/down-right advantage with the left hand when the back of the hand was faced (prone posture) and an upleft/down-right advantage for the right hand and upright/down-left advantage for the left hand when the palm was faced (supine posture). It is not evident why the pattern of results obtained for keypresses in the frontoparallel plane would be the mirror opposite of the pattern obtained for switch movements in the transverse plane, either in terms of salient features coding or end-state comfort. With regard to the salient features perspective, there is no obvi- 
ous reversal of reference frames between the two planes that could account for opposite effects. With regard to the end-state comfort perspective, the rotation preferences in the frontoparallel plane seem to be similar to those in the transverse plane, which leads to the same predictions as those for the unimanual studies.

To explain their results, Lippa and Adam (2001) made the assumption that when the hand is positioned in the frontoparallel plane, rotational preferences in the sagittal plane determine the movement preferences and, hence, the direction of the orthogonal SRC effect. They noted that the rotation preferences in the sagittal plane are clockwise and counterclockwise, respectively, for the left and the right hands in the prone posture, and the opposite for the two hands in the supine posture. When rotated $90^{\circ}$ in this plane, the finger farther from the subject can be coded as "up," and the finger closer to the subject can be coded as "down." With these assumptions, the obtained pattern of results is consistent with predictions based on end-state comfort. However, there is no apparent reason why rotation within a plane orthogonal to the one in which the response alternatives are aligned is crucial when the response is in the frontoparallel plane, whereas rotation within the response plane is crucial when the response is in the transverse plane. Thus, the explanation in terms of end-state comfort provided by Lippa and Adam for the specific hand posture effect they obtained requires a questionable assumption. Why their results are the mirror opposite of the other studies is an interesting issue whose resolution should lead to an increase in our understanding of the effects of hand posture on orthogonal SRC.

\section{Conclusion}

All accounts proposed to date for the first type of orthogonal SRC effect, the overall up-right/down-left advantage, attribute it to correspondence of asymmetric coding of the kind proposed from the salient features coding perspective (e.g., Adam et al., 1998; Cho \& Proctor, 2001; Weeks \& Proctor, 1990). However, several accounts of the second type of orthogonal SRC effects, those that vary as a function of response location and hand posture, attribute them to properties of the motor system (e.g., Lippa \& Adam, 2001; Michaels, 1989). The present study demonstrates that even in the domain to which the motor system accounts apply, correspondence of asymmetric stimulus and response codes provides a plausible explanation of the major findings. The additional tenets required for the explanation are that response location is coded with respect to multiple frames of reference and that the body of the hand provides one such frame. The response eccentricity effect was shown to add with that of hand posture, consistent with the view that it is based on coding of response location as left or right relative to a midline location, and the hand posture effect itself was shown to be due, at least in part, to location coding relative to the body of the hand. Moreover, the obtained results do not seem predictable in a straightforward manner on the basis of end-state comfort. Although some factors closely linked to response mode, such as hand posture, affect orthogonal SRC, the results of this and other studies imply that the overall up-right/down-left advantage and the orthogonal SRC effects that vary with anatomical factors are primarily functions of general properties of coding that do not depend on response mode.

\section{REFERENCES}

Adam, J. J., Boon, B., PaAs, F. G. W. C., \& Umiltà, C. (1998). The upright/down-left advantage for vertically oriented stimuli and horizontally oriented responses: A dual-strategy hypothesis. Journal of Experimental Psychology: Human Perception \& Performance, 24, 15821595.

Bauer, D. W., \& Miller, J. (1982). Stimulus-response compatibility and the motor system. Quarterly Journal of Experimental Psychology, 34A, 367-380.

Behrmann, M., \& Tipper, S. P. (1999). Attention accesses multiple reference frames: Evidence from visual neglect. Journal of Experimental Psychology: Human Perception \& Performance, 25, 83-101.

Carlson-Radvansky, L. A., \& Irwin, D. E. (1993). Frames of reference in vision and language: Where is above? Cognition, 46, 223-244.

Chase, W. G., \& Clark, H. H. (1971). Semantics in the perception of verticality. British Journal of Psychology, 62, 311-326.

Chо, Y. S., \& Proctor, R. W. (2001). Effect of an initiating action on the up-right/down-left advantage for vertically arrayed stimuli and horizontally arrayed responses. Journal of Experimental Psychology: Human Perception \& Performance, 27, 472-484.

Chо, Y. S., \& Proctor, R. W. (in press). Stimulus and response representations underlying orthogonal stimulus-response compatibility effects. Psychonomic Bulletin \& Review.

Ehrenstein, W. H., Schroeder-Heister, P., \& Heister, G. (1989). Spatial S-R compatibility with orthogonal stimulus-response relationship. Perception \& Psychophysics, 45, 215-220.

Hommel, B. (1997). Toward an action-concept model of stimulusresponse compatibility. In B. Hommel \& W. Prinz (Eds.), Theoretical issues in stimulus-response compatibility (pp. 281-320). Amsterdam: North-Holland.

Hommel, B., \& LipPa, Y. (1995). S-R compatibility effects due to contextdependent spatial stimulus coding. Psychonomic Bulletin \& Review, 2, 370-374.

Just, M. A., \& CARPEnTER, P. A. (1975). The semantics of locative information in pictures and mental images. British Journal of Psychology, 66, 427-441.

Kornblum, S., Hasbroucq, T., \& Osman, A. (1990). Dimensional overlap: Cognitive basis for stimulus-response compatibility-a model and taxonomy. Psychological Review, 97, 253-270.

KossLy n, S. M. (1994). Image and brain: The resolution of the imagery debate. Cambridge, MA: MIT Press.

Lamberts, K., Tavernier, G., \& D'Ydewalle, G. (1992). Effect of multiple reference points in spatial stimulus-response compatibility. Acta Psychologica, 79, 115-130.

LIPPA, Y. (1996). A referential-coding explanation for compatibility effects of physically orthogonal stimulus and response dimensions. Quarterly Journal of Experimental Psychology, 49A, 950-971.

LIPPA, Y., \& ADAM, J. J. (2001). An explanation of orthogonal S-R compatibility effects that vary with hand or response position: The endstate comfort hypothesis. Perception \& Psychophysics, 63, 156-174.

Michaels, C. F. (1989). S-R compatibilities depend on eccentricity of responding hand. Quarterly Journal of Experimental Psychology, 41A, 262-272.

Michaels, C. F., \& Schilder, S. (1991). Stimulus-response compatibilities between vertically oriented stimuli and horizontally oriented responses: The effects of hand position and posture. Perception \& Psychophysics, 49, 342-348.

Olson, G. M., \& LAXAR, K. (1973). Asymmetries in processing the terms "right" and "left." Journal of Experimental Psychology, 100, 284-290.

Olson, G. M., \& LAXar, K. (1974). Processing the terms right and left: 
A note on left-handers. Journal of Experimental Psychology, 102, 1135-1137.

Proctor, R. W., \& Cho, Y. S. (2001). The up-right/down-left advantage occurs for both subject-paced and computer-paced conditions: An observation on Adam, Boon, Paas, \& Umiltà (1998). Journal of Experimental Psychology: Human Perception \& Performance, 27, 466-471.

Proctor, R. W., Dutta, A., Kelly, P. L., \& Weeks, D. J. (1994). Crossmodal compatibility effects with visual-spatial and auditory-verbal stimulus and response sets. Perception \& Psychophysics, 55, 42-47.

Proctor, R. W., \& Pick, D. F. (1999). Deconstructing Marilyn: Robust effects of face contexts on stimulus-response compatibility. Memory \& Cognition, 27, 986-995.

Proctor, R. W., \& Reeve, T. G. (1985). Compatibility effects in the assignment of symbolic stimuli to discrete finger responses. Journal of Experimental Psychology: Human Perception \& Performance, 11, 623-649.

Proctor, R. W., \& Reeve, T. G. (1986). Salient-feature coding operations in spatial precuing tasks. Journal of Experimental Psychology: Human Perception \& Performance, 12, 277-285.

Proctor, R. W., WANG, H., \& VU, K.-P. L. (2002). Influences of different combinations of conceptual, perceptual, and structural similarity on stimulus-response compatibility. Quarterly Journal of Experimental Psychology, 55A, 59-74.

Reeve, T. G., \& Proctor, R. W. (1990). The salient-features coding principle for spatial- and symbolic-compatibility effects. In R. W. Proctor \& T. G. Reeve (Eds.), Stimulus-response compatibility: An integrated perspective (pp. 163-180). Amsterdam: North-Holland.

Riggio, L., GAWry SZEWSKI, L. G., \& UMiLtà, C. (1986). What is crossed in crossed-hand effects? Acta Psychologica, 62, 89-100.

Roswarski, T. E., \& Proctor, R. W. (1996). Multiple spatial codes and temporal overlap in choice-reaction tasks. Psychological Research, 59, 196-211.

ShAFFER, L. H. (1965). Choice reaction with variable S-R mapping. Journal of Experimental Psychology, 70, 284-288.

UMiltà, C. (1991). Problems of the salient-feature coding hypothesis: Comment on Weeks and Proctor. Journal of Experimental Psychology: General, 120, 83-86.

Umiltà, C., \& LiotTi, M. (1987). Egocentric and relative spatial codes in S-R compatibility. Psychological Research, 49, 81-90.

Umiltà, C., \& Nicoletti, R. (1990). Spatial stimulus-response compatibility. In R. W. Proctor \& T. G. Reeve (Eds.), Stimulus-response compatibility: An integrated perspective (pp. 89-116). Amsterdam: North-Holland.

Vu, K.-P. L., \& Proctor, R. W. (2002). The prevalence effect in twodimensional stimulus-response compatibility is a function of the relative salience of the dimensions. Perception \& Psychophysics, 64, 815-828

Vu, K.-P. L., Proctor, R. W., \& Pick, D. F. (2000). Vertical versus horizontal spatial incompatibility: Right-left prevalence with bimanual responses. Psychological Research, 64, 25-40.

Weeks, D. J., \& Proctor, R. W. (1990). Salient-features coding in the translation between orthogonal stimulus-response dimensions. Journal of Experimental Psychology: General, 119, 355-366.

WeEks, D. J., Proctor, R. W., \& Beyak, B. (1995). Stimulus-response compatibility for vertically oriented stimuli and horizontally oriented responses: Evidence for spatial coding. Quarterly Journal of Experimental Psychology, 48A, 367-383.

(Manuscript received June 20, 2001; revision accepted for publication April 30,2002.) 